\title{
儒家如何看待 $\mathrm{Al}$ 診斷技術的
}

\section{發展和應用}

\section{A Confucian Perspective on the \\ Development of AI Diagnostic}

\section{Technology}

\author{
張舜清 \\ Zhang Shunqing
}

\section{Abstract}

Cheng's article argues that AI diagnosis and its logic, which are based on Western medical thought and Western philosophy, obstruct the generation of meaning and construction of personhood for both doctors and patients. The article maintains that we should thus engage in introspection on $\mathrm{AI}$ in based on other traditions of thought, such as Confucianism. However the article does not provide a deeper

\footnotetext{
張舜清，中南財經政法大學哲學院教授，中國武漢，郵編：430073。

Zhang Shunqing, Professor, School of Philosophy, ZhongNan University of Economics and Law, Wuhan, China, 430073.

本文為國家社會科學基金專案 “宋代儒家生命倫理思想研究”（17BZX099）階段 成果。

《中外醫學哲學》XVII:2 (2019 年) : 頁 37-42。

International Journal of Chinese \& Comparative Philosophy of Medicine XVII:2 (2019), pp. 37-42.

(C) Copyright 2019 by Global Scholarly Publications.
} 
interpretation of why Confucianism is particularly helpful in constructing personhood and realizing value in life in the context of medical practice. This article is a response to Cheng's argument and suggests directions for refinement.

本文主要是基於對程國斌、武小西〈在 $\mathrm{AI}$ 醫生和病人之 間一人工智能診斷技術的內在邏輯及其對病人主體性建構的影 響〉一文（以下簡稱 “程文”）核心觀點的回應和評論。程文的 主要觀點是認為 AI 診斷技術的應用不僅影響到傳統的醫患關 係, 而且這種影響並不全是積極的、甚至破壞和消解掉了醫患關 係應當具備的一些重要價值原則。AI 診斷技術固然有助於提高醫 患雙方的主體性, 但是人作為人的生命意義的完整性卻在 “AI 醫 生” 這種缺乏情感和 “價值生成” 的機器面前, 無法得到有效照 顧, “AI 醫生” 沒有醫生作為有情感的人、有意義的人格而擁有 的人類性靈, 因而它無法真正取代醫生的作用, 因而 $\mathrm{AI}$ 診斷技術 的應用無可避免會造成對醫患關係本質內容——意義生成和人格 建構的傷害。而要解決這些問題, 僅僅從當代 AI 診斷技術發展與 應用的基本邏輯和支援這種技術發展的現代西方哲學思維出發則 無濟於事, 應當適度引進不同的邏輯和思維, 在這種認識背景下, 儒家思想被認為是一種可取的思想資源。(參見程國斌、武小西 文)

依據程文, 當代 AI 診斷技術應用的基本邏輯是建立在這種技 術所擁有的技術優勢以及由此帶來的巨大社會功效上。在資料資 訊足夠充分的情況下，AI 醫生可以高效完成各種醫療資料的判 斷、分析並作出結論, 從而更為精準、快捷地完成診斷, 其工作 效率和工作強度都遠非人類個體所能比擬, 而其可以批量生產、 系統作業的方式, 也能極大改善醫療資源緊張、醫患嚴重失衡的 問題。這樣一種邏輯, 我們可以稱之為 “技術效用主義”。而在 這種技術邏輯的背後, 則是來自西方本質主義和個體哲學觀的理 論支持。在本質主義的哲學思維中, 疾病被看作是 “獨立於人” 的一種客觀狀態, 有著客觀的本質, 因而生病就成為兩個實體性 
的存在一一疾病” 與 “人”一的衝突和對抗。對 “疾病” 的 本質主義理解，促成了西方醫學的知識論傳統，也促成了西醫基 本的診斷方式, 即通過發現和明確疾病的本質, 從而在已知的知 識系統中尋找匹配的名稱加以對應。而這正是發展 $\mathrm{AI}$ 診斷技術的 客觀前提。而西方的個體哲學觀視個體為自主、自足、能夠充分 自我實現的個體, 從而把個體的自主性、自由視為價值而格外重 視並加以維護, 而 $\mathrm{AI}$ 診斷技術的應用則有助於患者的自我診斷、 從而擺脱對醫生的依賴, 尤其是有助於將患者從家長式醫生的宰 製中解放出來, 從而極大提高患者的主體自由。但是程文認為, 這種哲學思維和邏輯絲毫不利於醫患雙方主體間性的建構, 而且 是對醫患雙方人格構建和生命意義的生成的嚴重傷害。（參見程 國斌、武小西文）為此，程文通過對傳統中醫診療思維和儒家自 我倫理觀的分析, 為解決上述問題提供了一種可能的中國方案。 不過, 程文並未就儒家是否支援 $\mathrm{AI}$ 診斷技術的應用提供具體觀點 和説明, 也未能從儒醫的社會本質角度、從醫學實踐與儒學旨趣 的內在關聯性更為明確、更為深刻地説明何以儒家思想更有利於 醫患雙方的人格建構和生命意義的完善。不過, 該文對 $\mathrm{AI}$ 診斷技 術應用的背後羅輯和哲學理據的討論, 則揭示出看待和解決 AI 診斷技術在臨床應用時所帶來的問題的一個根本著眼點, 為這種 問題的思考和解決提供了基本方向。

筆者以為, 從儒家思想的旨趣和追求來看, 儒家不會當然反 對 $\mathrm{AI}$ 診斷技術的發展和應用, 甚至在相當程度上表現為一種支持 力量, 而且由於醫學實踐本質上對於儒家而言屬於 “仁” 的社會 實践, 是一種践 “仁” 的方式, 因而醫生和醫療活動都並非是一 種單純的謀生職業和技術性活動, 人格構建和詮釋生命的價值和 意義, 本身就是 “仁” 的本質內涵和要求。也正是如此, 儒家思 想在維護生命意義和構建人格上才發揮出其獨特的價值。具體而 言 : 
其一，儒家的人本追求，促使儒家不會反對作為服務於人類 的助手的 $\mathrm{AI}$ 的發展。儒家的關心和追求始終與人類自身命運息息 相關, 只要發展 $\mathrm{AI}$ 技術的價值取向是人類自身, 那麼, 儒家沒有 理由反對這種技術的發展。並且, 儒家基於人本立場也會鮮明地 指出發展 $\mathrm{AI}$ 技術應當遵循的基本原則: 人自身的生命尊嚴和價值 不容侵犯, 發展 AI 技術必須要在人類的價值規範內進行。

其二, 在科學研究範圍內, 儒家應該不反對研製 “超級智慧 體” , 不反對人類借助技術對人體生理機能和心智慧力的提升改 造。儒家向來持一種大生命的宇宙觀, 認為人與萬物是同體同構 的, 在性質和存在意義上實際上存在同一性。（張舜清 2018）並 且儒家向來認為一切事物、包括人工物都不可能不遵循天道自然 的法則。對儒家而言, “人工”並非是人對天道自然法則的違背, 相反, 乃是人類遵循和運用天道自然法則改造自身的主體性活 動。而且, 後期儒家也發展出來一種人也是處於不斷進化過程中 的觀點，所謂 “質日代而形如一”（王夫之 1976，352）、“性 日生日成”（王夫之 $1976 ， 63$ ）即包含此意, 所以人類也不能以 恒定眼光來看待。

依上兩點, 筆者認為, 只要發展 $\mathrm{AI}$ 診斷技術是基於維護人類 生命的價值和意義、是以人的存在價值為前提, 那麼儒家應該不 會反對這種技術的發展與應用。不過, 人類應該持何種價值發展 自身, 中西哲學向來認識差異巨大。但這只是 “人類內部的矛盾 問題”，本質上是人類不同族群內部的價值衝突問題。基於價值 觀的差異, 中西對於是否發展 $\mathrm{AI}$ 技術會存在不同的理據和價值考 慮, 這是正常現象。非此即彼沒有出路, 重要的是尋求價值共識。 因而各方都不應該完全從自我文化立場試圖證明 “我方文化” 的 優越性，而是應該試圖尋找保證人類生存的共同出發點。毫無疑 問, 中西醫學和哲學都有自身的理論特色和解決問題的獨特方 式, 均是人類智慧的反映, 各自有各自的價值和歷史性。如果在 這方面陷入 “文化偏執”，則只會妨礙我們以包容態度面對不同 
傳統和吸收其中有價值的要素。儘管 $\mathrm{AI}$ 診斷技術的發展與應用主 要是基於西方哲學傳統和醫療思維發展起來的, 但這並不意味著 我們不應當對於這種價值依據進行反思和批判。或許正是基於這 種認識, 程文認為我們應當跳出西方哲學和診療思維的“窠 臼”，反觀自我文化的價值，從而為思考 $\mathrm{AI}$ 診㫁技術開闢不同的 思維場域和應用前景。

實事求是地説，建立在儒家哲學和價值基礎上的“儒醫”在 人格建構和生命的意義生成上的確有它特有的理論優勢。傳統中 醫遵循著中國哲學的 “天人合一”的思維，實踐著 “陰陽五行” 的宇宙觀念, 這種觀念視人類為宇宙內在的構成, 人的身體與宇 宙在存在性質上具有同一性, 本質上是在人與萬物一體的關聯性 中看待人的生命意義的生成和現實，這就從根本上避免了將患者 生命意義的生成和實現完全看成患者個體之事。並且，對於儒家 而言，醫學實踐本身是一種社會性的實踐 “仁” 的特殊方式，是 儒家 “仁政”的內在組成部分。儒家的 “仁”，本質上是為了實 踐天地之 “生德”, 講求的是一種生命之理, 如朱喜所謂 “仁是 生之理”（黎靖德 1986），它的核心內容即是維護生命的尊嚴和 價值、實現生命的意義, 在社會層面, 即表現為對民生的重視和 刻意維護。在這個意義上，“生病”被看作是 “不盡生理”，而 治病即是恢復 “生理” 的實踐行為，因而行醫和推行 “仁政”一 樣, 都是本著 “不忍人之心” 旨在維護和完善生命的活動。在儒 家這裡，醫療活動的實質也即醫生本著 “不忍人之心”通過恢復 患者的自然平衡而維護民生之舉, 因而它本質上是 “不忍人之 政” 的內在要求。而這也正是 “醫乃仁術” 的本質內涵。在這種 思維支配下, 醫生便不是一種單純的謀生職業, 醫療活動也不再 是一種單純的技術性活動, 而承載著社會治理和生命教化的重大 意義。醫生首先應當是一位 “仁者”, 至少應該是一位具備 “仁” 的情懷的人。正因為儒醫的這種本質屬性, 古人才有 “不為良相, 便為良醫”的追求。“良相”和“良醫”雖然職分有別，但追求 
一致, 皆為致仁, 在社會功能上二者一致, 皆以實現和維護人民 的生命為目的。故范仲淹才説: “果能為良醫也, 上以療君親之 疾, 下以救貧民之厄, 中以保身長年。在下能及小大生民者, 舍 夫良醫, 未之有也。”（吳曾 1979）一個真正的儒醫, 乃真正天 道流行的擔當者, 他對於患者著眼的不是利益, 而是怎樣重建他 的身體的自然平衡, 恢復其為人的尊嚴, 成就其生命的意義。儒 醫對人類所承擔的這種深刻而博厚的社會責任感, $\mathrm{AI}$ 醫生能夠提 供嗎? 何況人類是有情感的, 情感對於人類生命的品質有著不可 或缺的影響作用。而一個負責任的有仁心的“良醫”，其對於患 者整體的心性的修養和精神的健全亦有著非凡的作用與影響。而 西方哲學的本質主義思維以及個體倫理觀大有消解醫生在醫療中 的地位和作用, 甚至不要醫生的思想傾向。但是, 缺少了 “良醫” 在人格建構和完善生命意義上的主體性作用, 這更有利於患者成 就自身嗎? 這種追問，應當正是程文為我們提出的一個具有終極 性意義的問題，也是其主要價值所在。

\section{參考文獻 References}

王夫之: 《尚書引義》, 北京 : 中華書局, 1976 'WANG Fuzhi. The Quatation of Shangshu (Beijing: Zhonghua Book Company, 1976).

吳 曾: 《能改齋漫錄》, 上海：上海古籍出版社, 1979 , 頁 $381 \circ \mathrm{WU}$ Zeng. The Writings of Nenggai Study (Shanghai: Shanghai Ancient Books Publishing House, 1979), p.381.

張舜清: 《儒家生命倫理思想研究》, 北京: 人民出版社, 2018 , 頁 265 。

ZHANG Shunqing. The Study on the Thoughts of Confucian Bioethics (Beijing: People's Publishing House, 2018, p.265).

程國斌、武小西：〈在 AI 醫生和病人之間一人工智能診斷技術的內在 邏輯及其對病人主體性建構的影響〉, 《中外醫學哲學》, 2019 年, 第 XVII 卷, 第 2 期, 頁 11-36 ${ }^{\circ}$ CHENG Guobin and WU Xiaoxi. "Between AI Doctor and Patient: The Logic of AI Diagnosis and its Impact on Patient Subjectivity," International Journal of Chinese \& Comparative Philosophy of Medicine XVII:2 (2019), pp.11-36.

黎靖德編：《朱子語類》(第二冊), 北京：中華書局, 1986, 頁 498。 LI Jingde (ed). Zhuzi Yulei (Beijing: Zhonghua Book Company, 1986), p.498. 